\title{
Hyperuricemia in Glycogen Storage Disease Type I Contributions by Hypoglycemia and Hyperglucagonemia to Increased Urate Production
}

Joshua L. Cohen, Aaron Vinik, Jason Faller, and Irving H. Fox

Human Purine Research Center, Departments of Internal Medicine and Biological Chemistry,

University of Michigan, Ann Arbor, Michigan 48109

\begin{abstract}
Studies were performed to determine whether hypoglycemia or the glucagon response to hypoglycemia increases uric acid production in glycogen storage disease type I (glucose-6phosphatase deficiency). Three adults with this disease had hyperuricemia (serum urate, 11.3-12.4 mg/dl) and reduced renal clearance of urate (renal urate clearance, 1.1-3.1 $\mathrm{ml} / \mathrm{min}$ ). These abnormalities were improved in one patient by intravenous glucose infusion for 1 mo, suggesting a role for hypoglycemia and its attendant effects on urate metabolism and excretion.

A pharmacologic dose of glucagon caused a rise in serum urate from 11.4 to $13.0 \mathrm{mg} / \mathrm{dl}$, a ninefold increase in urinary excretion of oxypurines, a $65 \%$ increase in urinary radioactivity derived from radioactively labeled adenine nucleotides, and a 90\% increase in urinary uric acid excretion. These changes indicate that intravenous glucagon increases ATP breakdown to its degradation products and thereby stimulates uric acid production.

To observe whether physiologic changes in serum glucagon modulate ATP degradation, uric acid production was compared during saline and somatostatin infusions. Serum urate, urinary oxypurine, radioactivity, and uric acid excretion increased during saline infusion as patients became hypoglycemic. Infusion of somatostatin suppressed these increases despite hypoglycemia and decreased the elevated plasma glucagon levels from a mean of 81.3 to $52.2 \mathrm{pg} / \mathrm{ml}$.

These data suggest that hypoglycemia can stimulate uric acid synthesis in glucose-6-phosphatase deficiency. Glucagon contributes to this response by activating ATP degradation to uric acid.
\end{abstract}

\section{Introduction}

Hyperuricemia and gout occur commonly in glycogen storage disease type I (glucose-6-phosphatase deficiency) (1-3). Decreased renal excretion of urate secondary to lactic acidemia and ketonemia $(1,2,4,5)$ and elevated production of uric acid account for the hyperuricemia $(2,3,6,7)$.

The mechanisms for increased urate synthesis have been related to the hypoglycemia, which is a central feature of glucose-6-phosphatase deficiency (8-10). Hypoglycemia may

Reprint requests should be addressed to Dr. Fox, Clinical Research Center, University Hospital, Ann Arbor, MI 48109.

Received for publication 22 May 1984 and in revised form 6 September 1984.

J. Clin. Invest.

(C) The American Society for Clinical Investigation, Inc.

0021-9738/85/01/0251/07 \$1.00

Volume 75, January 1985, 251-257 have metabolic consequences related either to cellular glucopenia itself or to excess counterregulatory hormone release and subsequent activation of hepatic glycogenolytic pathways. A hypothesis has been formulated which proposes that hypoglycemia stimulates the secretion of glucagon, glucagon activates glycogen phosphorylase and the formation of phosphorylated sugars accentuated by the glucose-6-phosphatase deficiency, and the phosphorylation of sugars utilizes ATP which is degraded to uric acid (8-10) (Fig. 1). We have examined the role of glucagon in three patients with glucose-6-phosphatase deficiency by measuring ATP breakdown products during glucagon infusion and during suppression of plasma glucagon levels by somatostatin or glucose infusion.

\section{Methods}

Three unrelated women with glucose-6-phosphatase deficiency, 17-22 yr old, were studied in the Clinical Research Center at The University of Michigan Medical Center. The diagnosis was established in early childhood on the basis of typical clinical features, response to glucagon or epinephrine, and liver biopsy. One patient (S.G.) had a liver biopsy during a recent surgical procedure and was found to lack glucose-6phosphatase $(0.0 \mu \mathrm{mol} / \mathrm{min}$ per $\mathrm{g}$; normal range, $30-80 \mu \mathrm{mol} / \mathrm{min}$ per g) in assays performed by Dr. Rodney Howell of The University of Texas Medical School at Houston. Before entering the study, the subjects generally ate three meals each day and had intermittent 15 to $20 \mathrm{~g}$ dextrose supplements about six times each day. They usually awoke twice during the night for glucose supplements. All medications known to alter purine metabolism or excretion were discontinued at least 10 days before the studies.

Base-line studies. Throughout the study period, each patient received a weight-maintaining purine-free diet and ingested an additional 15$20 \mathrm{~g}$ of glucose supplements at their usual frequency above their 100 $120 \mathrm{~g}$ carbohydrate/d. Informed consent for all studies and procedures was obtained from the patients. The studies were approved by The University of Michigan Institutional Review Board.

To measure ATP degradation during spontaneous hypoglycemia, 4-5 $\mathrm{d}$ after admission each patient received $1.6 \mu \mathrm{mol}\left[8-{ }^{14} \mathrm{C}\right]$ adenine $(20 \mu \mathrm{Ci})$ intravenously. This radioactivity labels adenine nucleotides as follows:

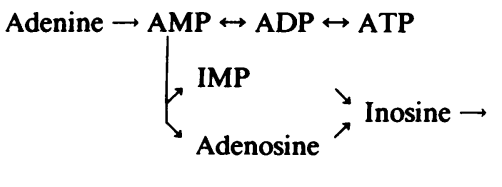

Hypoxanthine $\rightarrow$ Xanthine $\rightarrow$ Uric Acid

As ATP degrades to purine end-products, the urinary radioactivity excretion is a measure of the rate of ATP degradation (11).

Glucagon, somatostatin, or saline infusion. Patients were fasted for 6-8 $\mathrm{h}$ before infusion studies with glucagon, somatostatin, or normal saline. They received no intravenous or oral glucose supplements during the infusion studies unless they became symptomatically hypoglycemic. Hourly urine collections were obtained starting $2 \mathrm{~h}$ before infusion of glucagon or somatostatin and continued for 6-8 h. $1 \mathrm{mg}$ 


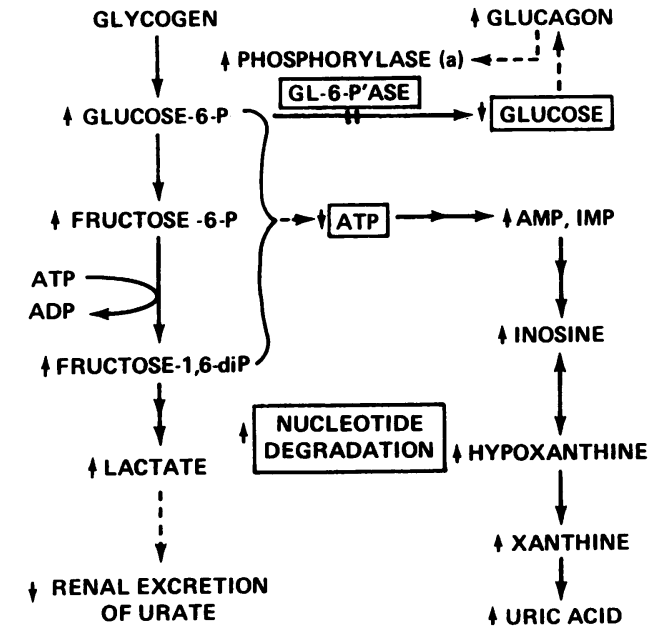

Figure 1. Hypothetical mechanism linking hypoglycemia to hyperuricemia in glucose-6-phosphatase deficiency. Hypoglycemia stimulates release of glucagon. This activates hepatic glycogen phosphorylase which degrades glycogen with trapping of phosphate in phosphorylated sugars. Cellular depletion of ATP occurs and increases intracellular concentrations of purine monophosphates which are subsequently degraded to uric acid. The phosphorylated sugars are converted to lactate which may block the renal excretion of urate. (This figure is reproduced from an article by I. H. Fox. 1981. Metabolic basis for disorders of purine nucleotide degradation. Metab. Clin. Exp. 30:616-634). IMP, inosine monophosphate.

glucagon (Eli Lilly Co., Indianapolis, IN) was dissolved in $50 \mathrm{ml}$ of normal saline and administered intravenously over $5 \mathrm{~min}$. Blood samples were collected through a heparin lock into plain or heparinized glass collection tubes at 60 and $15 \mathrm{~min}$ before and 15,30, 45, 60, and $120 \mathrm{~min}$ after the start of glucagon infusion. On another occasion, 500 $\mu g$ somatostatin (cyclic tetradecapeptide, Ayerst Co., Montreal, Canada) was dissolved in $100 \mathrm{ml}$ normal saline. $200 \mu \mathrm{g}$ in $40 \mathrm{ml}$ was delivered intravenously over $5 \mathrm{~min}$ and the remaining $300 \mu \mathrm{g}$ in $60 \mathrm{ml}$ was infused over $4 \mathrm{~h}(75 \mu \mathrm{g} / \mathrm{h})$. Blood samples were obtained 60 and 1 min before; 15, 30, 60, 120, 180, and $240 \mathrm{~min}$ after beginning; and $15,30,60,120$, and $180 \mathrm{~min}$ after cessation of the somatostatin infusion. An infusion of normal saline alone was also given instead of somatostatin on a separate occasion using the same experimental protocol. Blood glucose was monitored with an Ames dextrometer (Ames Division, Miles Laboratory, Elkhart, IN) and patients were given $50 \mathrm{ml}$ of $50 \%$ glucose by intravenous infusion when symptomatic hypoglycemia occurred. Experiments were performed on separate days with 1-3 d separation.

Assays. For analysis of lactate, $1.5 \mathrm{ml}$ of cold $1.0 \mathrm{M}$ perchloric acid was immediately added to $0.5 \mathrm{ml}$ of whole blood and shaken. For analysis of acetoacetate and betahydroxybutyrate, $1 \mathrm{ml}$ of cold $1.0 \mathrm{M}$ perchloric acid was added to $1 \mathrm{ml}$ of plasma and shaken. After centrifugation at $4^{\circ} \mathrm{C}$, supernatants were removed and stored at $-20^{\circ} \mathrm{C}$ until further analysis.

Serum electrolytes $\left(\mathrm{Na}, \mathrm{K}, \mathrm{HCO}_{3}\right.$, and $\left.\mathrm{Cl}\right)$ were assayed in the University Hospital Biochemistry Laboratory; glucose, cholesterol, triglycerides, lactate, ketones (acetoacetate and beta-hydroxybutyrate), insulin, human growth hormone, and glucagon were measured in The University of Michigan Diabetes Center Core Laboratories (12-19). Serum urate and urinary uric acid and oxypurines (hypoxanthine and xanthine) were assayed using enzymatic spectrophotometric techniques $(11,20,21)$. Creatinine was measured by an automated modification of the Jaffe reaction (22). Urinary radioactivity was measured by adding an $0.5 \mathrm{ml}$ aliquot of each urine sample to $5.0 \mathrm{ml}$ of Instagel (Packard Instrument Co., Inc., Downers Grove, IL). The mixture was counted in a liquid scintillation spectrometer system.

The data are presented as their absolute values or percent change from basal values. All data were stored, calculated, and plotted using Clinfo software on a $\operatorname{Vax} 11 / 730$. The number of patients was too small for statistical analysis of the effects of various interventions, but each patient served as their own control.

\section{Results}

Base-line values. Base-line studies (Table I) indicated metabolic abnormalities in all patients including lactic acidemia (serum lactate, 10.3-17.7 meq/liter) and hyperlipidemia (cholesterol, 290-394 mg/dl; triglyceride, 918-1,364 mg/dl). Two patients (S.G. and K.H.) had moderately elevated fasting glucagon concentrations $(72.4$ and $130 \mathrm{pg} / \mathrm{ml})$, while all had levels of insulin and growth hormone that were within the normal range. All three patients were markedly hyperuricemic with serum urate values ranging from 11.3 to $12.4 \mathrm{mg} / \mathrm{dl}$ (Table I). Urine uric acid excretion was not elevated (Table I). However, there was evidence for diminished renal clearance of urate in these patients with values of $1.1-3.1 \mathrm{ml} / \mathrm{min}$.

While the patients were off antihyperuricemic drugs and receiving glucose feeding, the $5 \mathrm{~d}$ cumulative urinary excretion of radioactive purines ranged from 2.3 to $5.8 \%$ of the administered dose, which is within or close to the limits established

Table I. Patient Profiles

\begin{tabular}{|c|c|c|c|c|}
\hline Patient & S.G. & M.G. & K.H. & $\begin{array}{l}\text { Normal } \\
\text { range }\end{array}$ \\
\hline Sex & $\mathbf{F}$ & $\mathbf{F}$ & $\mathbf{F}$ & \\
\hline Age & 22 & 17 & 22 & \\
\hline Weight (kg) & 60 & 54 & 49.5 & \\
\hline Height $(\mathrm{cm})$ & 150 & 152 & 153 & \\
\hline \multicolumn{5}{|l|}{ Creatinine } \\
\hline$(m g / d l)$ & 0.7 & 0.9 & 2.0 & $0.6-1.0$ \\
\hline \multicolumn{5}{|l|}{ Blood-urea } \\
\hline$(m g / d l)$ & 13 & 8 & 49 & $8-20$ \\
\hline \multicolumn{5}{|l|}{ Cholesterol } \\
\hline$(m g / d l)$ & 366 & 290 & 394 & $150-250$ \\
\hline \multicolumn{5}{|l|}{ Triglycerides } \\
\hline$(m g / d l)$ & 1,364 & 918 & 920 & $30-150$ \\
\hline \multicolumn{5}{|l|}{ Lactate } \\
\hline (meq/liter) & 13.5 & 17.9 & 10.3 & $0.40-1.19$ \\
\hline \multicolumn{5}{|l|}{ Beta-OH butyrate } \\
\hline (meq/liter) & 0.23 & 0.72 & 0.48 & $0.01-0.34$ \\
\hline \multicolumn{5}{|l|}{ Acetoacetate } \\
\hline (meq/liter) & 0.14 & 0.24 & 0.19 & $0.01-0.15$ \\
\hline \multicolumn{5}{|l|}{ Anion gap } \\
\hline (meq/liter) & 27 & 34 & 26 & $10-15$ \\
\hline \multicolumn{5}{|l|}{ Uric acid } \\
\hline$(m g / d l)$ & 11.3 & 11.4 & 12.4 & $2.7-7.8$ \\
\hline Insulin $(\mu U / m l)$ & 2.1 & 1.0 & 1.0 & $2-9$ \\
\hline \multicolumn{5}{|l|}{ Glucagon } \\
\hline$(p g / m l)$ & 72.4 & 46.5 & 130 & $36-54$ \\
\hline \multicolumn{5}{|l|}{ Growth hormone } \\
\hline$(n g / m l)$ & 1.6 & 1.7 & 1.9 & $0-5$ \\
\hline \multicolumn{5}{|l|}{ Urine uric acid } \\
\hline$(m g / 24 h)$ & 331 & 509 & 199 & $260-590^{*}$ \\
\hline
\end{tabular}

\footnotetext{
* $24 \mathrm{~h}$ urine uric acid excretion in normal volunteers on a purine-
} free diet (Seegmiller et al. [56]). 
in nine hyperuricemic gouty adults (11). This latter comparison is made with gouty patients because the turnover and excretion of uric acid is proportional to the serum urate concentration (11).

Continuous glucose infusion. The metabolic and hormonal responses during infusion of $20 \%$ glucose through a central venous catheter were assessed in one adult (S.G.) with glucose6-phosphatase deficiency. Therapy was initiated at a rate of 35 $\mathrm{ml} / \mathrm{h}$ and increased to $60 \mathrm{ml} / \mathrm{h}$ to maintain euglycemia for 1 mo. The patient continued to receive purine-free meals, but oral glucose supplements were discontinued. Serum urate levels decreased from between 10 and $11 \mathrm{mg} / \mathrm{dl}$ to $8.5 \mathrm{mg} / \mathrm{dl}$ within $2 \mathrm{~d}$ and to $7.9 \mathrm{mg} / \mathrm{dl}$ during the infusion (Fig. 2). The fractional uric acid clearance (urate clearance/creatinine clearance $\times 100$ ) rose from 3 to $3.5 \%$ within $4 \mathrm{~d}$ and increased further to $5.0 \%$ after $21 \mathrm{~d}$ of glucose infusion. The urine uric acid excretion did not substantially change during the infusion period. There was a gradual correction of the acidosis and the anion gap reached a nadir after $10 \mathrm{~d}$. Triglyceride levels fell progressively for the entire $21 \mathrm{~d}$ of the infusion to almost the normal range.

Glucose concentrations rose steadily from $80 \mathrm{mg} / \mathrm{dl}$ and averaged $130 \mathrm{mg} / \mathrm{dl}$ after $2 \mathrm{wk}$ of the glucose infusion. Plasma glucagon concentration fell from 80 to $40 \mathrm{pg} / \mathrm{ml}$ and remained low for the duration of the study. Serum insulin levels rose slightly after $2 \mathrm{~d}$ of infusion, but reached a maximum of 60 $\mu \mathrm{U} / \mathrm{ml}$ in $10 \mathrm{~d}$ and remained elevated for the duration of the study. Plasma growth hormone remained within normal limits.

These data show that the metabolic abnormalities of hypoglycemia, hyperuricemia, acidosis, and hyperlipidemia in glucose-6-phosphatase deficiency are correctable by the infusion of glucose. Glucose administration suppressed glucagon concentrations and eliminated cellular glucopenia. It is unclear which of these two variables causes hyperuricemia. Therefore, further studies were carried out to determine the relative contributions of hypoglycemia and the hyperglucagonemia to increased uric acid production.

Glucagon and uric acid production. If glucagon has a central role in increasing uric acid production, it should be possible to demonstrate the stimulation of ATP degradation following glucagon administration. Intravenous infusion of 1.0 mg glucagon over $5 \mathrm{~min}$ caused a transient tachycardia to a maximum heart rate of 113 beats/min and an increase in blood glucose concentration from 80 to $95 \mathrm{mg} / \mathrm{dl}$ (Fig. 3). This rise is similar to that observed by Tsalikian et al. (23) and is presumably related to the debranching enzyme. Serum lactate increased from 13.2 to $17.9 \mathrm{meq} / \mathrm{dl}$. There was also a rise in the levels of insulin and growth hormone (data not shown). Serum urate increased from $11.4 \mathrm{mg} / \mathrm{dl}$ to $13.0 \mathrm{mg} /$ dl. There was a ninefold rise in urinary excretion of oxypurines. Excretion of radiolabeled purines increased by $65 \%$ and excretion of uric acid increased by $90 \%$.

Suppression of glucagon by infusion of somatostatin. Although a pharmacologic dose of glucagon increases uric acid synthesis, this does not prove that a physiologic increase of endogenous glucagon causes these changes in glucose-6-phosphatase deficiency. Therefore, somatostatin was infused to decrease endogenous plasma glucagon levels and uric acid metabolism was examined. The study with somatostatin was compared with a separate control experiment in which only normal saline was infused.

During the infusion of saline alone, glucagon concentrations
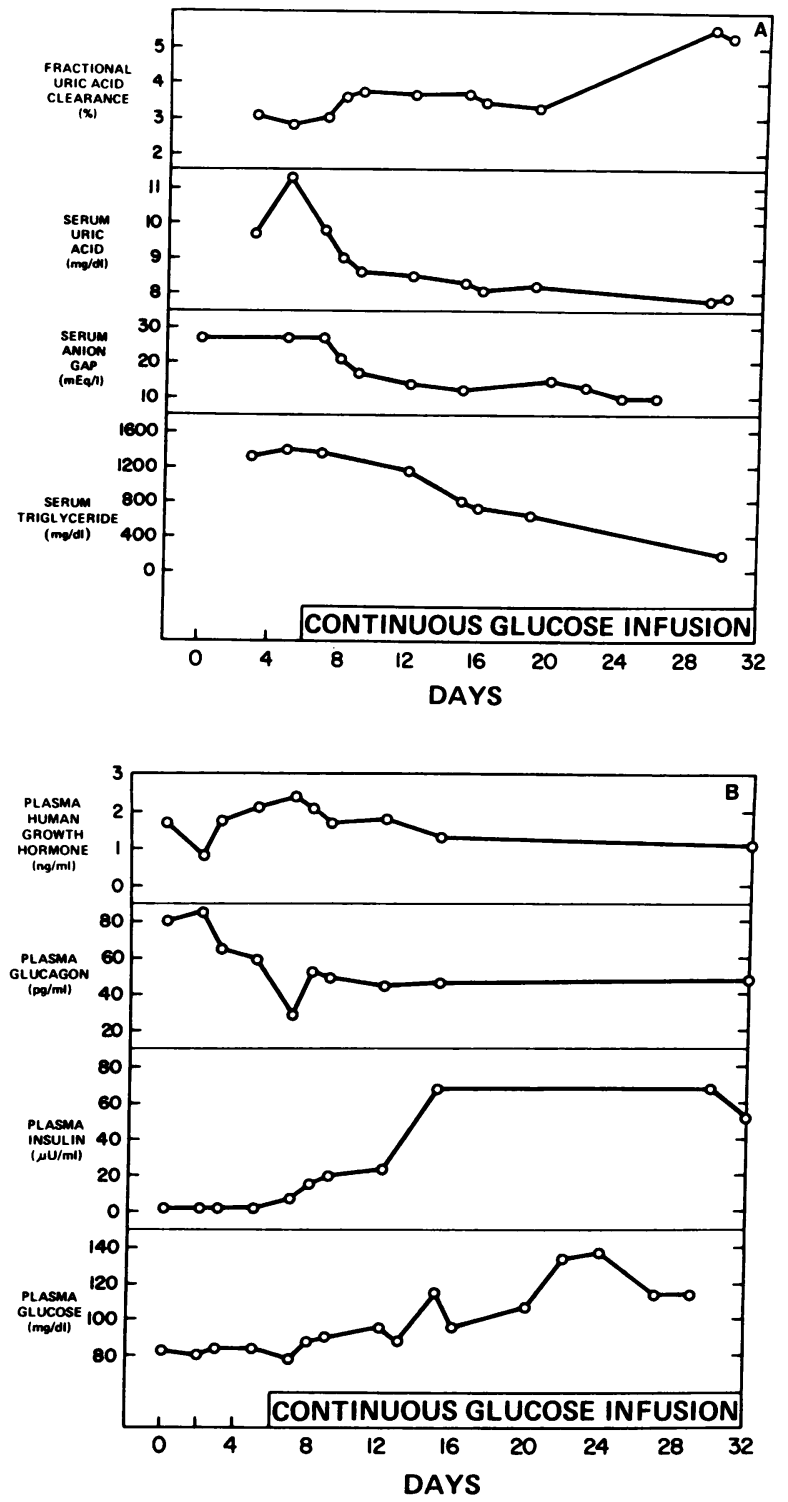

Figure 2. Metabolic and hormonal response to continuous glucose infusion. Continuous glucose infusion was given through a central venous catheter to patient S.G. Fractional clearance of uric acid, serum uric acid, anion gap, and serum triglycerides are shown in $(A)$, while plasma growth hormone, glucagon, insulin, and glucose are shown in $(B)$. Serum urate decreased from 11.3 to $7.9 \mathrm{mg} / \mathrm{dl}$ and fractional clearance of urate rose from 3 to $5 \%$ during the study period. Acidosis was corrected and serum triglycerides fell. Associated with these metabolic changes was a $40 \%$ reduction in serum glucagon from 78 to $45 \mathrm{pg} / \mathrm{ml}$.

increased by $30 \%$ above pretreatment levels (Fig. 4); this was presumably due to the falling blood glucose concentration. Growth hormone levels slowly increased from a base line of 2 $\mathrm{ng} / \mathrm{ml}$ to maximum values of 5-7 $\mathrm{ng} / \mathrm{ml}$. Serum urate levels, urine uric acid, oxypurine, and radiolabeled purine excretion were substantially elevated (Figs. 4 and 5). The following measures increased by the indicated mean percentages: serum urate, $10 \%$; urinary uric acid, $70 \%$; urine oxypurines, $270 \%$; and urinary radioactivity, $60 \%$. These measures indicate active ATP degradation to uric acid and its precursors during hypoglycemia. 

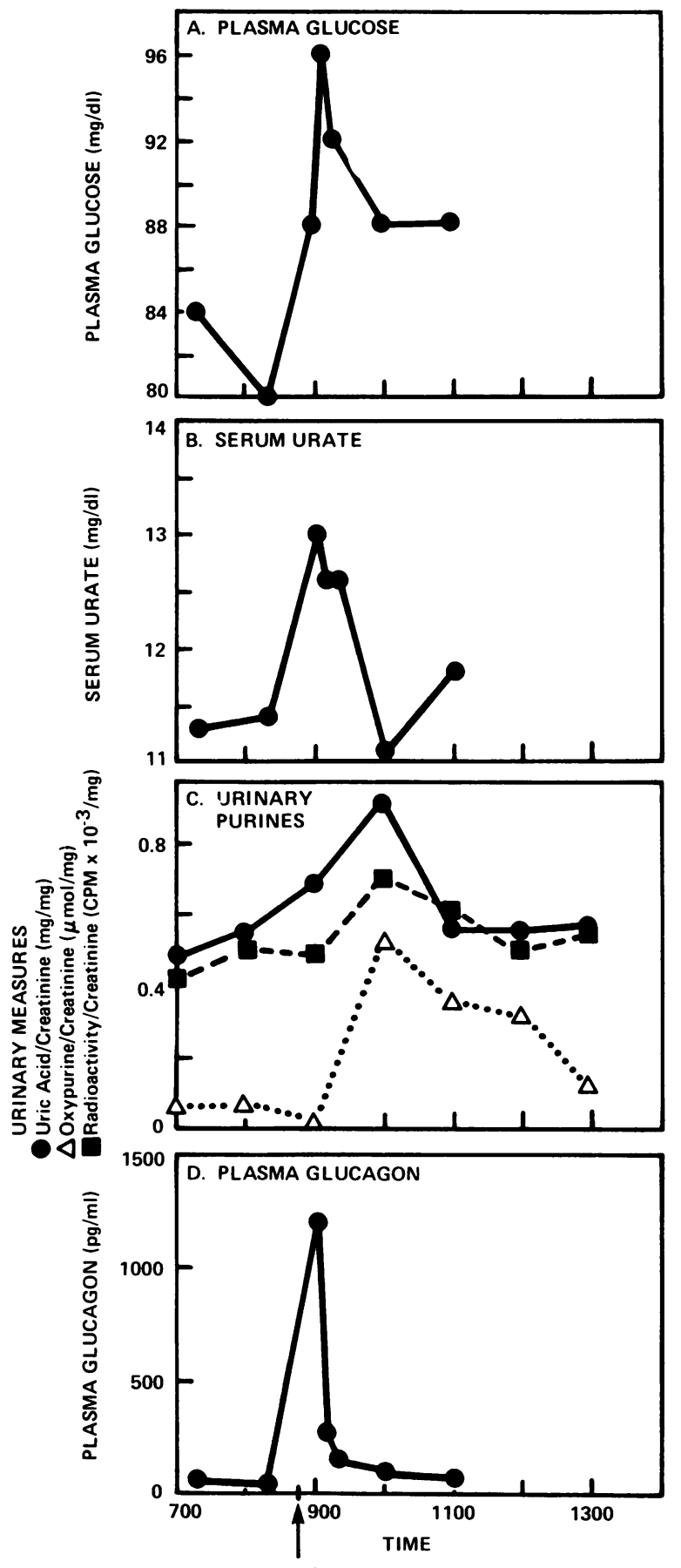

Figure 3. Metabolic and hormonal response to intravenous glucagon. $1 \mathrm{mg}$ of glucagon was infused in patient $\mathrm{S}$. G. at 0845 . Peak serum glucagon level at $15 \mathrm{~min}$ after infusion was $1,210 \mathrm{pg} / \mathrm{ml}$. ATP breakdown was stimulated as measured by the increase in serum urate from 11.3 to $13.0 \mathrm{mg} / \mathrm{dl}$, urinary uric acid, oxypurines, and radioactivity derived from $\left[8-{ }^{14} \mathrm{C}\right]$ adenine.

Infusion of somatostatin lowered the plasma glucagon levels from a mean of $81.3 \mathrm{pg} / \mathrm{ml}$ during the pretreatment period to $52.2 \mathrm{pg} / \mathrm{ml}$ during the somatostatin infusion (Fig. 4). Little or no change was evident in growth hormone levels with maximum values ranging from 3 to $10 \mathrm{ng} / \mathrm{ml}$. Serum

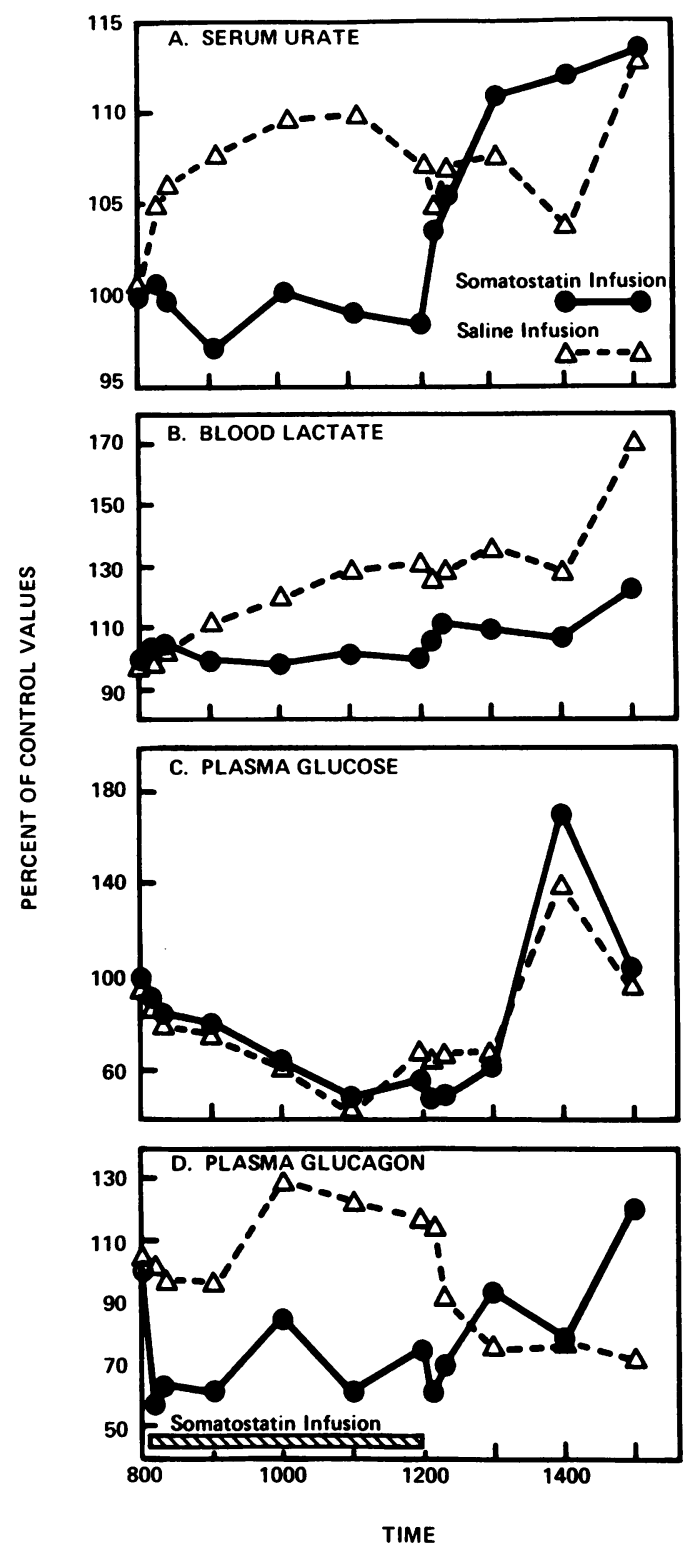

Figure 4. Metabolic and hormonal response to saline or somatostatin infusion. The response to a somatostatin infusion from 0800 to 1200 $h$ is compared with a saline infusion. The saline infusion was performed in two patients while the somatostatin infusion was performed in three patients. The changes in plasma levels are expressed as the mean percent of the base-line values obtained from 0600 to $0800 \mathrm{~h}$ as follows: $(A)$ plasma urate levels (mean base-line value, 12.1; range, $9.8-15.9 \mathrm{mg} / \mathrm{dl}$ ); $(B)$ blood lactate levels (mean base-line value, 13.8; range, 11.8-18.0 meq/liter); $(C)$ plasma glucose levels (mean base-line value, 61 ; range, $48-84 \mathrm{mg} / \mathrm{dl}$ ); $(D)$ plasma glucagon levels (mean base-line values, 82 ; range, $47-129 \mathrm{pg} / \mathrm{ml}$ ).

urate, urine uric acid, oxypurine, and excretion of radiolabeled purines were unchanged or decreased compared with base-line values (Figs. 4 and 5). Thus, with infusion of somatostatin, there was no stimulation of ATP degradation despite hypoglycemia which was similar to that during saline infusion (Fig. 4). With cessation of somatostatin infusion, there was a rebound rise in serum urate, urine radioactivity, and urine oxypurine excretion. 

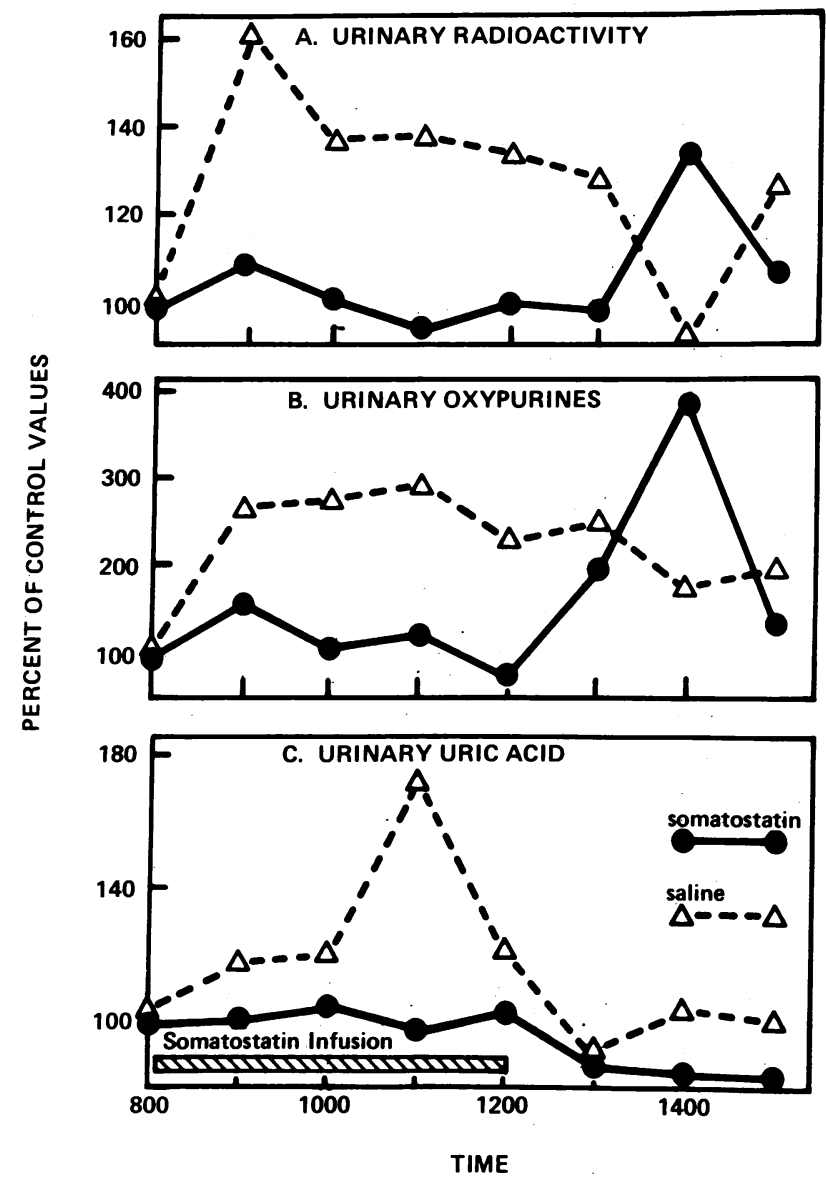

Figure 5. Urinary purine response to saline or somatostatin infusion. The studies are the same as described in Fig. 4. The changes in urinary excretion are expressed as the mean percent of base-line values obtained from 0600 to $0800 \mathrm{~h}$ as follows: $(A)$ Urinary radioactivity excretion (mean base-line value, $4.0 \times 10^{2}$; range, 3.2-5.4 $\times 10^{2} \mathrm{cpm} / \mathrm{mg}$ creatinine); $(B)$ Urinary oxypurine excretion (mean base-line value, 0.21 ; range, $0.11-0.36 \mu \mathrm{mol} / \mathrm{mg}$ creatinine);

(C) Urine uric acid excretion (mean base-line value, 0.5 ; range, $0.33-$ $0.74 \mathrm{mg} / \mathrm{mg}$ creatinine).

\section{Discussion}

Hyperuricemia and gout occur frequently in glucose-6-phosphatase deficiency $(1-10,24-26)$. The hyperuricemia results from both a decreased renal clearance of urate secondary to lactic acidemia $(1,4,5)$ and ketonemia (2) and increased production of uric acid $(2,3,6,7)$. Decreased renal clearance of urate was evident in the three patients studied (Table I).

Accelerated ATP degradation in response to hypoglycemia and the release of glucagon has been proposed as a cause for uric acid overproduction in glucose-6-phosphatase deficiency (Fig. 1) (8-10). The activation of glycogen phosphorylase by glucagon leads to glycogenolysis and formation of glucose-6phosphate. In the absence of glucose-6-phosphatase, only limited quantities of free glucose can be formed in the liver probably from debrancher enzyme activity (23). Continuing formation of phosphorylated sugars (2) leads to trapping of inorganic phosphate and depletion of ATP (9). Under these conditions, purine nucleoside monophosphates may accumulate and in turn are degraded to uric acid. An analogous mechanism underlies the hyperuricemia accompanying disorders of fructose metabolism $(10,27)$ and the accelerated ATP degradation following fructose infusion in subjects with normal enzyme activity (28-32).

The proposed model has been evaluated in our experiments. Correction of hypoglycemia suppresses plasma glucagon levels and reverses cellular glucopenia. Sustained normalization of blood sugar by either intravenous or intragastric infusion of nutritional supplements corrects the metabolic abnormalities including hyperuricemia and growth retardation of children with glucose-6-phosphatase deficiency (33-40). In our study, acidosis, hyperlipidemia, and hyperuricemia were improved by continuous intravenous glucose infusion (Fig. 2). Plasma glucagon concentrations were lowered during this therapy in our studies and in previous experiments $(33,41)$. These findings are consistent with the hypothesis that glucagon stimulates uric acid production. However, since hypoglycemia was eliminated, it is difficult to attribute the changes in uric acid levels to the reduction in glucagon levels alone.

Glucagon administration increases the serum urate levels in patients with glucose-6-phosphatase deficiency (9). Pharmacologic doses of intravenous glucagon lowered hepatic ATP content and increased hepatic concentrations of phosphorylated sugars. These metabolic alterations accompanied an acute rise in the serum urate level. Our studies support the association between glucagon injection and uric acid metabolism, since a pharmacologic dose of glucagon elevated the serum urate level, the urinary oxypurines, uric acid, and radioactivity originating from labeled ATP. However, these observations do not prove that glucagon is responsible for increasing ATP degradation in glucose-6-phosphatase deficiency, since endogenous plasma glucagon levels are only modestly increased to $<10 \%$ of the values achieved in these pharmacologic experiments.

Central to the model presented, linking hypoglycemia to purine degradation, is the concept that endogeneous release of hypoglycemia counterregulatory hormones should activate ATP breakdown to uric acid in patients with glucose-6-phosphatase deficiency. Untreated patients have elevated glucagon levels $(33,41)$, which may be a response to chronic hypoglycemia $(37,42)$. We tested the hypothesis that the elevated glucagon concentration causes the hyperuricemia of glucose-6-phosphatase deficiency by examining the responses to suppression of glucagon levels during the infusion of somatostatin. Infusion of somatostatin lowered the plasma glucagon level and simultaneously reduced the serum urate level, urinary uric acid, oxypurine, and radiolabeled purine excretion as compared with the values observed during a saline infusion under identical conditions. With cessation of the somatostatin infusion, there was a rebound rise in plasma glucagon paralleled by a rise in serum urate, urinary oxypurine excretion, and urinary radioactivity excretion. These changes provide evidence that activation of ATP degradation to uric acid is regulated in part by the increase in endogenous plasma glucagon levels. However, it remains to be determined whether physiologic glucagon replacement of levels suppressed by the infusion of somatostatin will stimulate ATP degradation.

While it may be speculated that the hyperuricemia response results entirely from glucagon release during hypoglycemia, the possibility exists that other factors mediate the accelerated ATP degradation to uric acid during hypoglycemia. In normal subjects, plasma concentrations of glucagon, catecholamines, 
growth hormone, and cortisol all increase with hypoglycemia (42-44). Changes in growth hormone levels do not seem to account for alterations of uric acid synthesis, since changes were modest and did not correspond with increases of ATP degradation. However, both glucagon and catecholamines can rapidly stimulate glycogenolysis and gluconeogenesis and are the most important hormonal counterregulatory factors which increase glucose production in response to hypoglycemia in normal humans (45-50). We cannot exclude the possibility that catecholamines released during hypoglycemia may contribute to the increased uric acid synthesis of glucose-6phosphatase deficiency. However, this seems less likely since somatostatin infusion diminished the hyperuricemic response to hypoglycemia and somatostatin does not alter catecholamine levels (50).

Accelerated ATP degradation and increased production of urate, which contribute to the hyperuricemia of glucose-6phosphatase deficiency, may be important in other clinical disorders. Increased ATP breakdown to uric acid accounts for the hyperuricemia secondary to hypoxia, vigorous muscular exercise, ethanol intake, inborn errors of fructose metabolism, fructose infusion, and possibly a subgroup of patients with primary hyperuricemia and overproduction of uric acid (10, 27-32, 51-55). It seems possible that abnormalities in glucose metabolism or the hormonal mediators regulating glucose availability could be factors involved in the pathogenesis of hyperuricemia in some gouty patients.

\section{Acknowledgments}

The authors wish to thank the nurses and dietitians of The University of Michigan Clinical Research Center for excellent patient care, Dr. Rodney Howell of Texas Medical Center at Houston for assaying glucose-6-phosphatase in a liver biopsy specimen, Sally Jones and Sandy DeBruyne for technical assistance, Holly Gibson for typing the manuscript, and Stephen Schmaltz for his assistance in the data analysis using Clinfo.

This work was supported by U. S. Public Health Service grants 2R01 AM 19674, 5M01RR42, and 5P60AM 20572. Dr. Faller was a postdoctoral fellow supported by the Arthritis Foundation.

\section{References}

1. Howell, R. R., D. M. Ashton, and J. B. Wyngaarden. 1962. Glucose-6-phosphatase deficiency glycogen storage disease. Studies on the interrelationships of carbohydrate, lipid and purine abnormalities. Pediatrics. 29:553-565.

2. Howell, R. R. 1965. The interrelationship of glycogen storage disease and gout. Arthritis Rheum. 8:780-785.

3. Alepa, F. P., R. R. Howell, J. R. Klinenberg, and J. E. Seegmiller. 1967. Relationships between glycogen storage disease and tophaceous gout. Am. J. Med. 42:58-66.

4. Jeandet, J., and H. Lestradet. 1961. L'hyperlactacidemie, cause probable de l'hyperuricemie dans la glycogenase hepatique. Rev. Fr. Etud. Clin. Biol. 6:71-72.

5. Fine, R. N., J. Strauss, and G. N. Donnell. 1966. Hyperuricemia in glycogen-storage disease type I. Am. J. Dis. Child. 112:572-576.

6. Jakovcic, S., and L. B. Sorensen. 1967. Studies of uric acid metabolism in glycogen storage disease associated with gouty arthritis. Arthritis Rheum. 10:129-134.

7. Kelley, W. N., F. M. Rosenbloom, J. E. Seegmiller, and R. R. Howell. 1968. Excessive production of uric acid in type I glycogen storage disease. J. Pediatr. 72:488-496.

8. Roe, R. F., and M. D. Kogut. 1977. The pathogenesis of hyperuricemia in glycogen storage disease, type I. Pediatr. Res. 11:664669.

9. Greene, H. L., F. A. Wilson, P. Heffernan, A. B. Terry, J. R. Moran, A. E. Slonim, T. M. Claus, and I. M. Burr. 1978. ATP depletion, a possible role in the pathogenesis of hyperuricemia in glycogen storage disease type I. J. Clin. Invest. 62:321-328.

10. Fox, I. H. 1981. Metabolic basis for disorders of purine nucleotide degradation. Metab. Clin. Exp. 30:616-634.

11. Edwards, N. L., D. Recker, and I. H. Fox. 1979. Overproduction of uric acid in hypoxanthine-guanine phosphoribosyltransferase deficiency. Contribution by impaired purine salvage. J. Clin. Invest. 63:922-930.

12. Mellanby, J., and D. H. Williamson. 1974. Acetoacetate. In Methods of Enzymatic Analysis. H. Bergmeyer, editor. Academic Press, New York. Second ed. 1840-1843.

13. Williamson, D. M., and J. Mellanby. 1974. Beta-hydroxybutyrate. In Methods of Enzymatic Analysis. H. Bergemeyer, editor. Academic Press, New York. Second ed. 1836-1839.

14. Gutman, I., and A. W. Wahlefeld. 1974. Lactate. Methods of Enzymatic Analysis. H. Bergemeyer, editor. Academic Press, New York. Second ed. 1464-1468.

15. Hayashi, M., J. C. Floyd, Jr., S. S. Fajans, and S. Pek. 1977. Insulin, proinsulin, glucagon and gastrin in pancreatic tumors and in plasma of patients with organic hyperinsulinism. J. Clin. Endocrinol. Metab. 44:681-694.

16. Pek, S., S. S. Fajans, J. C. Floyd, Jr., R. F. Knopf, and J. W. Conn. 1972. Failure of sulfonylureas to suppress plasma glucagon in man. Diabetes. 21:216-223.

17. Bergmeyer, H. U., F. Bernt, F. Schmidt, and M. Stark. 1974. D-Glucose. In Methods of Enzymatic Analysis. H. Bergemeyer, editor. Academic Press, New York. Second ed. 1196-1201.

18. Bondar, R. J., and D. C. Mead. 1974. Evaluation of glucose-6phosphate dehydrogenase from leuconostoc mesenteroids in the hexokinase method for determining glucose in serum. Clin. Chem. 20:586590.

19. Glick, S. M., J. Roth, R. S. Yalow, and S. A. Berson. 1963. Immunoassay of human growth hormone in plasma. Nature (Lond.). 199:784-787.

20. Liddle, L., J. E. Seegmiller, and L. Laster. 1959. The enzymatic spectrophotometric method for determination of uric acid. J. Lab. Clin. Med. 54:903-913.

21. Klinenberg, J. R., S. Goldfinger, K. H. Badley, and J. E. Seegmiller. 1967. An enzymatic spectrophotometric method for the determination of xanthine and hypoxanthine. Clin. Chem. 13:834836.

22. Technicon Auto Analyzer R Method File. 1969. Method N 116. Technicon Instruments Corp., Tarrytown, New York.

23. Tsalikian, E., P. Simmons, C. Howard, and M. W. Haymond. 1982. Near normal glucose production in type I GSD. Pediatr. Res. 16:265A.

24. Kolb, O. F., R. S. DeLalla, and J. W. Gorman. 1955. The hyperlipidemias in disorders of carbohydrate metabolism, serial lipoprotein studies in diabetic acidosis with xanthomatosis and in glycogen storage disease. Metab. Clin. Exp. 4:310-317.

25. Jeune, M., A. Charrat, and J. Bertrand. 1957. Polycori hepatique, hyperuricemie et goutte. Arch. Fr. Pediatr. 14:897-909.

26. Jeune, M., R. Francois, and B. Jarlot. 1959. Contribution a l'etude des polycories glycogeniques du foie. Rev. Int. Hepatol. 9:133.

27. Gitzelmann, R., B. Steinmann, and G. Van den Berghe. 1983. Essential fructosuria, hereditary fructose intolerance and fructose $1,6-$ diphosphatase deficiency. In The Metabolic Basis of Inherited Disease. J. B. Stanbury, J. B. Wyngaarden, and D. S. Fredrickson, editors. McGraw Hill, New York. Fifth ed. 118-140.

28. Perheentupa, J., and K. Raivio. 1967. Fructose-induced hyperuricemia. Lancet. II:528-531.

29. Maenpaa, P. H., K. O. Raivio, and M. P. Kekomaki. 1968. 
Liver adenine nucleotides: fructose-induced depletion and its effect on protein synthesis. Science (Wash. DC). 161:1253-1254.

30. Woods, H. F., L. V. Eggleston, and H. A. Krebs. 1970. The cause of hepatic accumulation of fructose 1-phosphate on fructose loading. Biochem. J. 119:501-510.

31. Fox, I. H., and W. N. Kelley. 1972. Studies on the mechanism of fructose-induced hyperuricemia in man. Metab. Clin. Exp. 21:713721.

32. Raivio, K. O., M. O. Becker, L. J. Meyer, M. L. Greene, G. Nuki, and J. E. Seegmiller. 1975. Stimulation of human purine synthesis de novo by fructose infusion. Metab. Clin. Exp. 24:861-869.

33. Slonim, A. E., W. W. Lacy, A. Terry, H. L. Greene, and I. M. Burr. 1979. Nocturnal intragastric therapy in type I glycogen storage disease: effect on hormonal and amino acid metabolism. Metab. Clin. Exp. 28:707-715.

34. Crigler, J. F., and J. Folkman. 1978. Glycogen storage disease: new approaches to therapy. Ciba Found. Symp. 55:331-356.

35. Greene, H. L., A. E. Slonim, J. A. O'Neill, and I. M. Burr. 1976. Continuous nocturnal intragastric feeding for management of type I glycogen storage disease. $N$. Engl. J. Med. 294:423-425.

36. Davidson, A. G. F., L. T. K. Wong, L. Kirby, W. J. Tze, J. M. Rigg, and D. A. Applegarth. Glycogen storage disease type I: effect of continuous nocturnal nasogastric feeding. Monogr. Hum. Genet. 9:29-36.

37. Ehrlich, R. M., B. H. Robinson, H. H. Freedman, and N. J. Howard. 1978. Nocturnal intragastric infusion of glucose in management of defective gluconeogenesis with hypoglycemia. Am. J. Dis. Child. 132:241-243.

38. Perlman, M., M. Aker, and A. E. Slonim. 1979. Successful treatment of severe type I glycogen storage disease with neonatal presentation by nocturnal intragastric feeding. J. Pediatr. 94:772-774.

39. Greene, H. L., A. E. Slonim, I. M. Burr, and J. R. Moran. 1980. Type I glycogen storage disease: five years of management with nocturnal intragastric feeding. J. Pediatr. 96:590-595.

40. Benke, P. J., and S. Gold. 1978. Uric acid metabolism in therapy of glycogen storage disease type I. Pediatr. Res. 12:204-206.

41. Okada, S., Y. Seino, H. Kodama, T. Yutaka, K. Inui, M. Ishida, M. Yabuuchi, and Y. Seine. 1979. Insulin and glucagon secretion in hepatic glycogenoses. Acta Paediatr. Scand. 68:735-738.

42. Gerich, J. E., V. Schneider, S. E. Dippe, M. Langlois, C. Noacco, J. Karam, and P. Forsham. 1974. Characterization of the glucagon response to hypoglycemia in man. J. Clin. Endocrinol. Metab. 38:77-82.
43. Garber, A. J., P. E. Cryer, J. V. Santiago, M. W. Haymond, A. S. Pagliara, and D. M. Kipnis. 1976. The role of adrenergic mechanisms in the substrate and hormonal response to insulin-induced hypoglycemia in man. J. Clin. Invest. 58:7-15.

44. Gerich, J., J. Davis, M. Lorenzi, R. Rizza, N. Bohannon, J. Karam, S. Lewis, R. Kaplan, T. Schultz, and P. Cryer. 1979. Hormonal mechanisms of recovery from insulin-induced hypoglycemia in man. Am. J. Physiol. 236:E380-E385.

45. Exton, J. G., L. Mallette, and L. Jefferson. 1970. The hormonal control of hepatic gluconeogenesis. Recent Prog. Horm. Res. 26:411455.

46. Exton, J. G., G. A. Robison, E. W. Sutherland, and C. R. Park. 1971. Studies on the role of adenosine 3',5'-monophosphate in the hepatic actions of glucagon and catecholamines. J. Biol. Chem. 246:6166-6177.

47. Young, J. B., and L. Landsberg. 1977. Catecholamines and intermediary metabolism. Clin. Endocrinol. Metab. 6:599-631.

48. Palmer, J. P., D. P. Henry, J. W. Benson, D. G. Johnson, and J. W. Ensinck. 1976. The glucagon response to hypoglycemia in sympathectomized man. J. Clin. Invest. 57:522-525.

49. Clarke, W. S., J. V. Santiago, L. Thomax, M. W. Haymond, E. Ben-Galim, and P. E. Cryer. 1979. The role of adrenergic mechanisms in recovery from hypoglycemia in man: studies with adrenergic blockade. Am. J. Physiol. 236:E147-E152.

50. Rizza, R. A., P. E. Cryer, and J. E. Gerich. 1979. Role of glucagon, catecholamines, and growth hormone in human glucose counter regulation. Effects of somatostatin and combined alpha and beta-adrenergic blockade on plasma glucose recovery and glucose flux rates after insulin-induced hypoglycemia. J. Clin. Invest. 64:62-71.

51. Woolliscroft, J. O., H. Colfer, and I. H. Fox. 1982. Hyperuricemia in acute illness: a poor prognostic sign. Am. J. Med. 72:58-62.

52. Sutton, J. R., C. J. Toews, G. R. Ward, and I. H. Fox. 1980. Purine metabolism during strenuous muscular exercise in man. Metab. Clin. Exp. 29:254-260.

53. Faller, J. L., and I. H. Fox. 1982. Ethanol-induced hyperuricemia: evidence for increased urate production by activation of adenine nucleotide turnover. N. Engl. J. Med. 307:1598-1602.

54. Hers, H.-G., and G. Van Den Berghe. 1979. Enzyme defect in primary gout. Lancet. I:585-586.

55. Van Den Berghe, G., and H.-G. Hers. 1980. Abnormal AMP deaminase in primary gout. Lancet. II: 1990.

56. Seegmiller, J. E., A. I. Grayzel, L. Laster, and L. Liddle. 1961. Uric acid production in gout. J. Clin. Invest. 40:1304-1314. 